Proceedings of the New Zealand Grassland Association 49:81-86 (1988)

\title{
VARIATION AMONG PERENNIAL RYEGRASS X TALL FESCUE PLANTS FROM TISSUE CULTURE
}

A. G. Scott and D. W. R. White

Grasslands Divisions, DSIR, Palmerston North

Abstract

Tissue culture was used in an attempt to obtain a fertile perennial ryegrass $x$ tall fescue hybrid. Regenerated hybrid plants were found to be morphologically variable and contain extensive chromosome rearrangements. Spontaneous chromosome doubling had occurred as well as chromosome elimination, though no fertile hybrid plants have been obtained to date.

Keywords: somaclonal variation, Lolium perenne, Festuca arundinacea, intergeneric hybrids.

\section{INTRODUCTION}

In creating a hybrid between perennial ryegrass (Lolium perenne) and tall fescue (Festuca arundinacea), it is possible to combine the general palatability of perennial ryegrass with the hardiness and persistence of tall fescue. Hybrids created have been generally sterile, though fertility can be restored by doubling the chromosome number. Chromosome doubled plants have been found to be unstable and experience chromosome loss. Thus one of the main obstacles in breeding a perennial ryegrass $x$ tall fescue hybrid is overcoming the problem of hybrid instability.

Whole plants can be regenerated from plant cells grown in tissue culture. Cells cultured as a callus (unorganised group of cells) can undergo sponteaneous permanent changes (somaclonal variation) and some of this variation is reflected in the plants (somaclones) regenerated from callus cultures (Larkin \& Scowcrofl 1981). Somaclones derived from the same parent have been found to differ in a variety of characters such as leaf width, tiller density, habit and chromosome number and structure.

The technique of tissue culture offers alternative approaches to obtaining fertile, stable perennial ryegrass $x$ tall fescue hybrids through tissue culture induced mutation, chromosome doubling or introgression. The rate of spontaneous mutation generated is very high when compared to natural spontaneous mutation rates (Evans \& Sharp 1986) and thus it is possible that a fertile variant may be created by spontaneous mutation. Fertility in intergeneric hybrids can often be restored by doubling the hybrid's chromosome number (Cocking 1984). In general the chromosome number of grasses is difficult to double by conventional techniques (Rybczynski et al. 1983) whereas spontaneous chromosome doubling occurs frequently in callus tissue culture and has been exploited as a means of obtaining chromosome doubled plants in a wide variety of species (Karp \& Bright 1985). The enhanced level of chromosome rearrangement and elimination obtained in callus tissue culture can be used to facilitate introgressive breeding (Larkin \& Scowcroft 1981) involving the incorporation of desirable plant genes from one species into another. An extensive backcrossing programme is normally required in introgressive breeding and is thus dependent on some fertility in the created hybrids. It is also tedious, time consuming and sometimes unsuccessful. Tissue culture offers a mechanism whereby chromosome shuffling can be obtained without the requirement for backcrossing. It is also possible that a stable chromosome configuration is obtained during the chromosome shuffling process that results in subsequent plant fertility.

We have produced somaclones of a number of perennial ryegrass $x$ tall fescue hybrids to determine whether the tissue culture process can be used to produce a stable, fertile hybrid. 


\section{METHODS}

Emasculated flowers of a perennial ryegrass plant $(2 n=14)$ were crossed with pollen from four different tall fescue plants $(2 n=6 x=42)$. A plant of the SR1 genotype was selected as the ryegrass parent in the cross since callus from this genotype has been previously demonstrated to produce a prolific number of highly variable somaclones. immature embryos resulting from these crosses were dissected out and cultured on Murashige \& Skoog (1964) media with $2.0 \mathrm{mg} \mathrm{2,4-D}$ and $0.01 \mathrm{mg} \mathrm{BAP}$ per litre. Callus cultures were established from four different embryos (lines $\mathrm{H}_{1}, \mathrm{~Hz}, \mathrm{H}_{3}, \mathrm{H}_{4}$ ) and plantlets were regenerated on MS media with $0.01 \mathrm{mg}$ BAP per litre. Mature plants were assessed for morphological variation. Four replicates of each somaclone were grown under glasshouse conditions in a randomised split block design. Measurements were taken from the first fully expanded leaf from mature tillers. Chromosome counts were determined from root-tip squashes.

\section{RESULTS AND DISCUSSION}

\section{Regeneration}

Thirty eight plants were regenerated from the four callus lines. Most of the regeneration (67\%) occurred in the $\mathrm{H} 2$ and $\mathrm{H} 5$ series. The genotype of the tall fescue parent apparently influenced the amount of regeneration from the hybrid cultures. The frequency of perennial ryegrass regeneration is also known to be genotype dependent (unpublished results). Overall plantlet regeneration was very poor in comparison with SR1 perennial ryegrass regeneration. Only a small number of plantlets were obtained from each cross in the first subculture. In the second subculture it was possible to obtain only a few plantlets from one line.

\section{Somaclonal variation}

Somaclonal variation (both morphological and cytological) was exhibited in 3 out of the 4 lines. No variation was observed among somaclones of the $\mathrm{H} 5$ series. Others (Karp \& Bright 185) Scowcroft 1985) have also noted that the amount of somaclonal variation observed is influenced by the genotype of the plant. Thus the ability to regenerate and the frequency of variation are both factors influenced by the genotype of the plant but are independent of each other.

Only a few plants were obtained in the $\mathrm{H}_{3}$ and $\mathrm{H}_{4}$ series. All of the plants examined had tissue culture induced chromosome changes (table 1). Hybrid plants resulting from a cross between diploid perennial ryegrass $(2 n=14)$ and hexaploid tall fescue $(2 n=5 x=42)$ would be expected to have a chromosome number of 28 (the haploid complement of the two parental genomes). Somaclones from both $\mathrm{H}_{3}$ and $\mathrm{H}_{4}$ series had more than the expected number of chromosomes.

Most of the somaclonal variation occurred in the $H_{2}$ series (tables 1 and figure 1). Figure 2 describes the most probable phylogeny of somaclonal events that occurred in the series. Somaclones obtained from the second subculture $\left(\mathrm{H}_{2} \mathrm{~S}_{2}\right)$ were more variable than those derived from the first subculture. This is in agreement with the general observation that higher rates of somaclonal variation are associated with increased periods of tissue culture (Scowcroft 1985).

One highly polyploid (more than two sets of chromosomes) somaclone $\left(\mathrm{H}_{2} \mathrm{~S}_{1} 15\right)$ was observed within the $\mathrm{H}_{2}$ series. This plant was unstable and contained cell lines with different chromosome numbers but stable counts were obtained from a few tillers. These tillers were maintained as separate lines. Highly polyploid cells are known to be unstable and it appears that there has been chromosome erosion until a stable chromosome configuration was reached. Mean leaf width measurements obtained from the stable and mixoploid tillers were considerably smaller than in other somaclones in the $\mathrm{H}_{2} \mathrm{~S}_{1}$ series (see Figure 2). Karp \& Bright (1985) also note that increased ploidy levels can reduce plant vigour. 


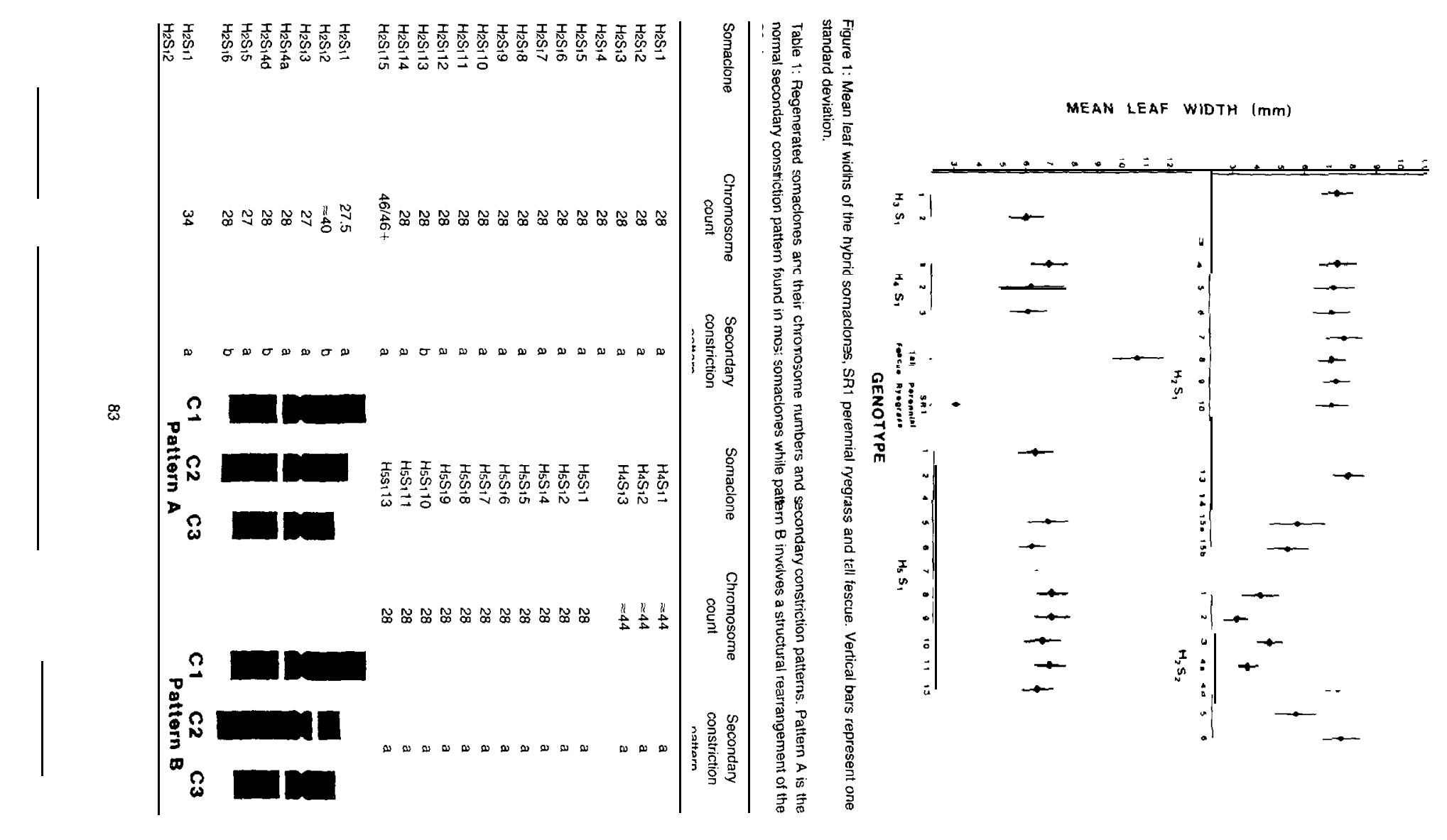


Three of the 28 chromosomes in the karyotype possessed prominent secondary constrictions and were able to be individually recognised. A structural rearrangement involving the $\mathrm{C} 2$ chromosome was observed in some of the somaclones from the first and second subcultures in the $\mathrm{H}_{2}$ series (see Table 1). Thus all these plants were probably descended from the same cell line (see Figure 2). The rearrangement involved the movement of the secondary constriction from the long arm to the short arm of C2 chromosome (see Table 1). Most of the somaclones with this structural rearrangement

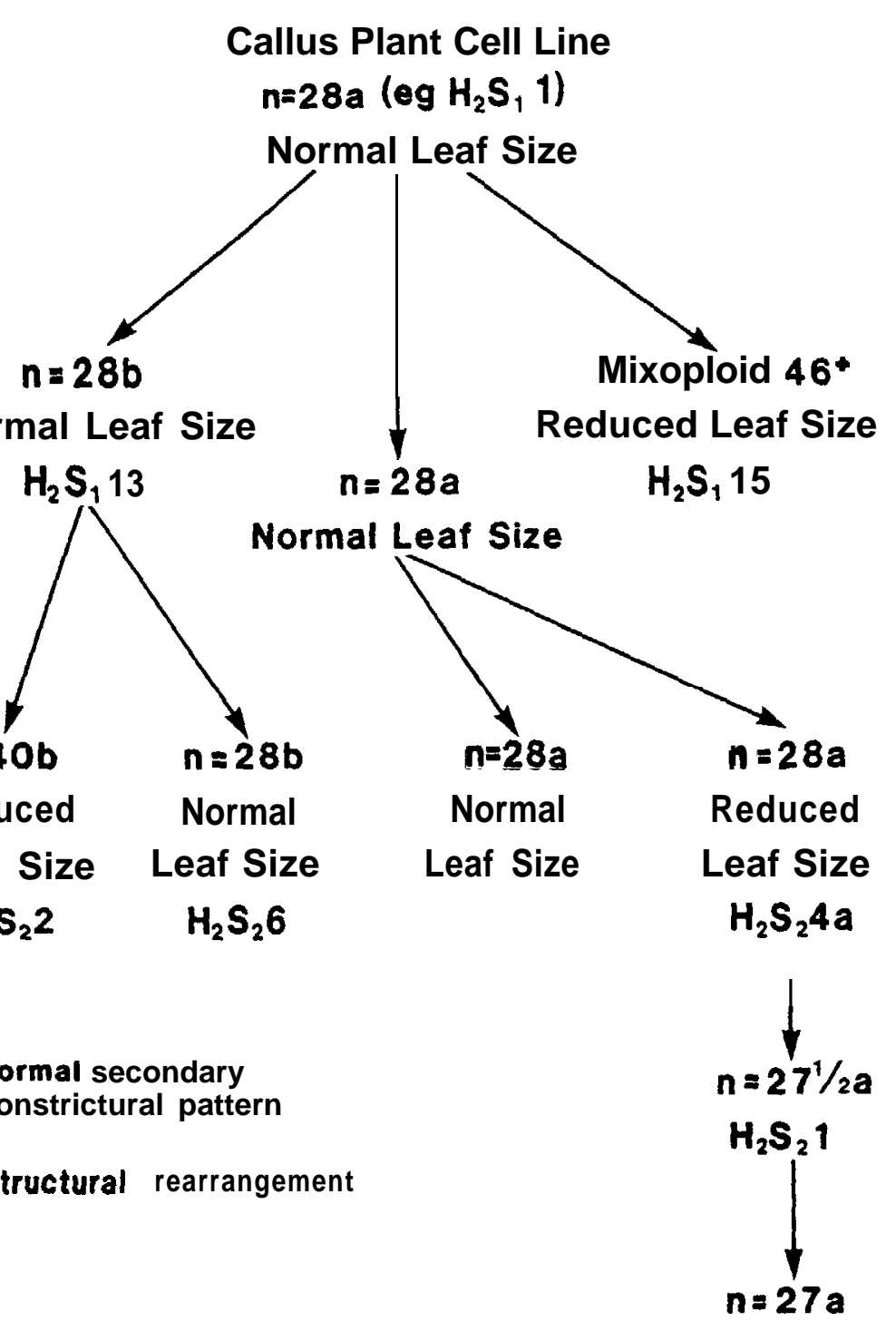

Figure 2: Phylogeny of the tissue culture induced events that occurred $\mathrm{H}_{2} \mathrm{~S}_{2} 3 \& \mathrm{H}_{2} \mathrm{~S}_{2} \mathrm{~S}$ in the $\mathrm{H} 2$ cell line. 
showed no reduction in vigour when compared with other somaclones of this series. The fact that these somaclones were morphologically normal is not unusual since structural chromosome rearrangements often have no effect on the phenotype (Karp \& Bright 1985). Other structural rearrangements may also have occurred but would be detectable at mitosis only if they produced a visible change in chromosome morphology (Jones 1978). Since it was not possible to identify all individual chromosomes, other changes could have easily been missed. Structural changes are more readily detectable at meiosis. Because the hybrid plants in this study were sterile and did not produce anthers this form of analysis was not possible.

Among the $\mathrm{Hz}$ somaclones from the second subculture were some very fine leaved regenerants (Figure 1). Unlike the other somaclones, these plants were not intermediate in size between tall fescue and perennial ryegrass, but closely resembled the SR1ryegrass parent in leaf size and tiller density. These plants were an example of somaclonal induced mutation not involving visible chromosomal change. Cytologically normal, fine leaved variants have also been observed among ryegrass somaclones derived from the SR1 perennial ryegrass parent used in this study (White, this proceedings).

Chromosome elimination was observed in some of the fine leaved somaclones (see Table 1). These somaclones showed no reduction in vigour when compared with other cytologically normal, fine leaved somaclones. Thus in this case, aneuploidy (chromosome loss or gain) was not affecting the vigour of these plants. Although aneuploidy is one of the most detrimental chromosome changes and is usually associated with reduced plant vigour, Karp \& Bright (1985) note that not all aneuploids are grossly abnormal. It is also possible that the polyploid nature of the hybrid (as it derives 3 sets of chromosomes from its tall fescue parent) may buffer it against the effects of aneuploidy.

Despite the extensive chromosomal changes produced in tissue culture we were unable to produce a fertile perennial ryegrass $x$ tall fescue hybrid. Evidence of chromosomal rearrangements that could facilitate introgression and polyploidy events were obtained, though a completely doubled $(2 n=56)$ amphidiploid plant was not found. This was surprising since Kasperbauer et a/. (1979) have successfully used tissue culture to obtain amphidiploid $(2 n=56)$ annual ryegrass $x$ tall fescue hybrids. They experienced no difficulty in regeneration and found that $8 \%$ of somaclones regenerated from late subcultures were amphidiploid. They also observed phenotypic variation among the somaclones involving changes in leaf width. As in this study, they found plants with very narrow leaves but Kasperbauer et al. (1979) also found a similar number of wide leaf regenerants. The phenotypic variation obtained in the perennial ryegrass $x$ tall fescue hybrids is potentially very useful. If for example an amphidiploid plant was obtained, tissue culture could be used to generate variation within the line.

Rybczynski et a/. (1983) have also used tissue culture to induce chromosome doubling in a variety of Lolium x Festuca hybrids. Of the 154 somaclones regenerated, $14 \%$ were found to be amphidiploid. However, they were unable to obtain any regeneration from perennial ryegrass $x$ tall fescue hybrid callus cultures.

To obtain an amphidiploid perennial ryegrass $x$ tall fescue hybrid it may be necessary to incorporate colchicine in the tissue culture media as this chemical would enhance the level of chromosome doubling. For the process of introgression to be successful, genetic exchange between the parental genomes must occur as well as chromosome elimination. We obtained some chromosome rearrangement and some chromosome loss. The herbicide CIPC induces chromosome loss (Roth \& Lark 1984). By including CIPC in the tissue culture media, it may be possible to increase the amount of chromosome elimination and thus facilitate introgression.

Given the success of other workers in obtaining amphidiploid plants from other Lolium $x$ Festuca hybrids, it should be possible to also obtain a perennial ryegrass $x$ tall fescue amphidiploid using tissue culture now that we are able to regenerate plants from callus. 


\section{References}

Cocking E.C. 1964. Hybridization past and present. In: Ammirato P.V.. Evans D.A., Sharp W.R.. Yamada Y. (Eds.) Handbook of Plant Cell Culture. Macmillan Publishing Company, New York, pp. 1-8.

Evans D.A., Sharp W.A. 1966. Applications of somaclonal variation. Bio/technology 4: 528-532.

Jones K. 1976. Aspects of chromosome evolution in higher plants. Advances in Botanical Research 6: 119-194.

Karp A.. Bright S.W.J. 1986. On the causes and origins of somacional variation. Oxford Surveys of Plant Molecular end Cell Biology 2: 199-234.

Kasperbauer M.J., Buckner R.C.. Bush L.P. 1979. Tissue culture of annual negrass $x$ tall fescue $F_{1}$ hybrids. Crop Science 19: 457.460 .

Larkin P.J., Scowcroft W.R. 1961. Somaclonal variation - a novel source of variability from cell cultures. Theoretical \& Applied Genetics 60: 197-214.

Murashige T.. Skoog F. 1962. A revised medium for rapid growth and bio assays with tobacco tissue cultures. Physiologica Plantanum 15; 473-497.

Roth E.J., Lark K.G. 1964. Isopropyl-N-(3 chlorophenyl) carbamate (CIPC) induced chromosome loss in soybean. a new tool for plant somatic cell genetics. Theoretical \& Applied Genetics 68: 421-431.

Rybczynski J.J.. Zwierzykowski Z., Slusarkiewicz-Jarzina A. 1983. Plant regeneration with doubled chromosome number in tissue culture of $F_{1}$ Lolium-Festuca hybrids. Genetica Polonica 24(1): 1-8.

Scowcroft W.R. 1985. Somaclonal variation: The myth of clonal uniformity. In: Hohn B., Dennis ES. (Eds.) Genetic flux in plants. Springer -- Verlag, Wien, pp. 217-245. 